\title{
PERIODISMO EDUCACIONAL: ESTADOS UNIDOS, DO SÉCULO 19 ÀS PRIMEIRAS DÉCADAS DO SÉCULO 20
}

DOI:

http://dx.doi.org/10.1590/2236-3459/204895.16

Mirian Jorge Warde

Universidade Federal de São Paulo - campus de Guarulhos, Brasil.

\section{$\cos 80$}

\section{Resumo}

Este artigo está apoiado em pesquisa de periódicos educacionais lançados nos Estados Unidos entre o século 19 e as primeiras décadas do século 20. Para este estudo foram rastreados repositórios de arquivos e bibliotecas norte-americanos e levantada bibliografia pertinente ao assunto do período referido. A lista de periódicos contemplada neste trabalho inclui 653 títulos dos quais foram analisadas, a partir de tendências predominantes em diferentes conjunturas, características tais como o local de produção, o editor, o público pretendido e seus objetivos.

Palavras-chave: periodismo educacional, periódico escolar, associação docente, Estados Unidos.

\section{EDUCATIONAL JOURNALISM: THE UNITED STATES, FROM THE $19^{\text {TH }}$ CENTURY TO THE EARLY DECADES OF THE $20^{\text {TH }}$ CENTURY}

\section{Abstract}

This paper is supported by research on educational journals issued in the United States between the $19^{\text {th }}$ century and the early decades of the $20^{\text {th }}$ century. For this study, repositories of U.S. archives and libraries were tracked down and the bibliography relevant to the subject in the mentioned period was surveyed. The list of journals included in this work has 653 titles out of which I conducted an analysis, starting from the prevailing tendencies in different situations, of characteristics such as the place of production, the editor, and intended public and its objectives. Key-words: educational journalism, school journal, teachers' association, United States.

\section{PERIODISMO EDUCACIONAL: ESTADOS UNIDOS, DESDE EL SIGLO 19 HASTA LAS PRIMERAS DÉCADAS DEL SIGLO 20}

Resumen

Este artículo está apoyado en investigación de periódicos educacionales lanzados en los Estados Unidos entre el siglo 19 y las primeras décadas del siglo 20. Para este estudio fueron rastreados repositorios de archivos y bibliotecas norteamericanas, y levantada la bibliografía pertinente al asunto del período referido. La lista de periódicos contemplados en este trabajo incluye 653 títulos 
de los cuales fueron analizados, a partir de tendencias predominantes en diferentes coyunturas, características tales como el local de producción, el editor, el público pretendido y sus objetivos.

Palabras-clave: periodismo educacional, periódico escolar, asociaciones docentes, Estados Unidos.

\section{PRESSE EDUCATIONNELLE: ETATS-UNIS, DU $19^{\mathrm{E}}$ SIECLE AUX PREMIERES DECENNIES DU 20E SIECLE}

\section{Résumé}

Cet article porte sur une recherche de périodiques pédagogiques parus aux Etats-Unis entre le $19^{\mathrm{e}}$ siècle et les premières décennies du $20^{\mathrm{e}}$ siècle. Pour cette étude, des fonds d'archive et des bibliothèques nord-américaines ont été recensées et une bibliographie en lien avec le sujet a été identifiée. La liste de périodiques dont il est question dans ce travail comprend 653 titres desquels ont été analysées, à partir de tendances prédominantes en différents contextes, des caractéristiques telles le lieu de production, l'éditeur, le public visé et les objectifs.

Mots-clé: presse éducationnelle, périodique scolaire, associations enseignantes, Etats-Unis. 


\section{Introdução}

Os Estados Unidos, desde os primeiros tempos republicanos, editores individuais ou em grupo deram ampla divulgação aos seus lançamentos por meio de estatísticas, listagens, boletins, repositórios, diretórios, dentre outros (Warde, 2011). Essa massa de dados e informações produzida por motivações comerciais, com o tempo, deu base a um considerável número de estudos sobre o movimento editorial norte-americano nos séculos coloniais e nos primeiros momentos republicanos, com destaque à produção e comercialização de livros e jornais, bem como aos títulos e autores. Adentrando ao século 20, nota-se que o interesse se ampliou de modo que aos estudos sobre aquelas modalidades de impressos - livros e jornais acrescentaram-se outros sobre a produção e circulação dos magazines, embora em quantidades significativamente menor (Mott, c1958-1968).

Essas modalidades permaneceram, até os dias atuais, como objetos de diferentes tipos pesquisa, acadêmicas ou comerciais. O que ocorreu ao longo do tempo é que os primeiros estudos de amplo escopo, que buscavam traçar um panorama do mercado livreiro ou de jornais e magazines, deu lugar a estudos tópicos, de menor abrangência quantitativa, porém mais detalhados (Hudson, 1873). Assim, passadas as primeiras décadas do século 20, os trabalhos acadêmicos, ao menos esses, optaram pela pesquisa verticalizada de um magazine, de um jornal, de uma editora ou, no âmbito da História da Educação, de um pequeno número de livros didáticos de uma disciplina específica em um curto período de tempo.

Esse preâmbulo visa a não apenas destacar a vasta literatura analítica e a massa disponível de dados e informações sobre impressos naquelas modalidades acima destacadas - livros, jornais e, em menor escala, magazines - mas principalmente registrar a ausência de programas investigatórios, nos Estados Unidos, de largo escopo e duração, sobre os impressos seriais em geral e os journals em particular, embora haja um elevado número de trabalhos bastante específicos a respeito de determinados periódicos de certas áreas, em determinado período de tempo ${ }^{1}$.

Este artigo apresenta um balanço abrangente e analítico dos periódicos educacionais - em diferentes modalidades de especialização ou de destinação - lançados nos Estados Unidos, de 1810 até a década de 1920. Para compor a base de dados aqui explorada foram utilizados alguns poucos trabalhos datados de fins do século 19 e início do 20 (Barnard,1865; Bardeen, 1881, 1893; Towne, 1909; Monroe, 1918, 1919; Davis, 1919; Ryan, 1923; National Education Association, 1930; Shannon, 1931; Mclnerny, 1989), acrescidos das listagens, repositórios e diretórios acadêmicos norte-americanos antigos e atuais.

Considerando o período abarcado, bem como a inclusão em suas fontes de periódicos educacionais destinados tanto a professores, funcionários de escolas primárias, pais e dirigentes da educação, quanto a acadêmicos, este artigo não parte de uma prévia definição das modalidades de impressos abordadas, uma vez que estavam, muitos deles, ensaiando tipos que, tempos depois, seriam ou não consagrados, inaugurando novos ou aprimorando antigos meios de comunicação entre os agentes

\footnotetext{
1 Sobre programas investigatórios de largo escopo e duração ver, dentre os europeus, Caspard (19811991); Caspard-Karydis (2000-2005). Dentre os brasileiros, alguns bons exemplos: Bastos (1994); Catani, Bastos (1997); Biccas (2008); Catani (2003). 
escolares, ou estabelecendo padrões de distinção para os veículos de comunicação acadêmica. Não por acaso muitos dos impressos seriados incluídos neste estudo denominavam-se journal ainda que não guardassem as características que hoje se reservam a esse tipo, assim como outros se chamavam bulletin, gazette ou magazine e, no entanto, guardavam os mesmos padrões de outros denominados journal?.

A expressão educational journalism, alusiva aos educational periodicals como categoria específica de impressos, estava em circulação nos Estados Unidos em meados do século 19. Henry Barnard a utiliza em publicação de 1851 considerando aqueles periódicos um dos instrumentos fundamentais para a formação do magistério, além das escolas normais (Barnard, 1851a). Bardeen ${ }^{3}$ (1881) repete a expressão sem qualquer esclarecimento adicional, o que leva a supor que, assim como para Barnard de uns quinze anos antes, as definições implicadas nos impressos periódicos ainda não o preocupavam.

Descrição mais minuciosa de educational journalism aparecerá no verbete journals and journalism, educational do volume 3 da Cyclopedia of Education organizada por Paul Monroe (1918): trata-se da modalidade de publicação profissional especializada que se desenvolve somente com o crescimento de uma profissão. Essa é a explicação utilizada para os educational journals profissionalizados terem surgido apenas em meados do século 19. Tais revistas, journals profissionais, foram antecedidas por um tipo de publicação denominado de educational journals que pretendia criar um sentimento popular em favor da educação pública. Essas, por seu turno, foram precedidas por um tipo de publicação que era concebida para incrementar a condição intelectual geral da população. O desenvolvimento das publicações profissionais seguiu de perto o desenvolvimento das associações educacionais.

Outro empenho de definição aparece na tese de doutorado publicada por Sheldon Emmor Davis em 1919, ao explicar os critérios e procedimentos adotados para compor seus dados sobre o periodismo educacional nos Estados Unidos do século 19. Ainda assim, Davis confessa a dificuldade enfrentada para se manter dentro dos critérios por ele mesmo estabelecidos em um ambiente no qual faltaria consenso sobre o que seria o educational journalism.

O estudo de Davis incide sobre "os periódicos destinados à promoção da educação escolar pública, os que lidam com a história ou o estudo científico da educação ou a técnica do trabalho de sala de aula, o aperfeiçoamento dos professores e as notícias escolares gerais" (1919, p. 5). O entendimento de Davis sobre o periodismo educacional é

\footnotetext{
${ }^{2}$ Vale lembrar que no inglês praticado nos Estados Unidos, no Reino Unido e países coligados, hoje se entende por journal a revista acadêmica especializada de destinação específica, enquanto o termo magazine é utilizado para a revista de ampla circulação, que geralmente se pode comprar livremente em bancas de jornal ou revistarias. Ainda no âmbito dos periódicos o newspaper se refere ao que chamamos em língua portuguesa de jornal. Quanto à expressão educational journalism, a ser logo apresentada, eu já a encontrei consagrada no início do século 20 utilizada na Cyclopedia coordenada por Paul Monroe.

${ }^{3}$ Bardeen foi editor e publicador do School Bulletin, uma vez que respondia pela edição e também pela produção do periódico em sua casa editorial C. W. Bardeen Publisher, em Syracuse, NY. O leitor sabe que em inglês editor corresponde "a person who is in charge of and determines the final content of a newspaper, magazine, or multi-author book. A person who commissions or prepares written or recorded material for publication or broadcast" (Oxford online). O dicionário Cambridge online sugere como traduções: editor e redator-chefe. Quanto ao publisher em inglês, tanto pode se referir à casa editorial, quanto ao editor no sentido acima.

Hist. Educ. [Online] $\quad$ Porto Alegre

v. 20

ก. 48

Jan./abr., 2016

p. $95-120$
} 
convergente com a Cyclopedia (Monroe, 1918) e com o que já se insinuava em Barnard (1851a): "revistas escolares ("school journals"), no sentido restrito de periódicos para docentes como uma classe, não poderiam existir antes de existir um bem definido grupo de professores que, de algum modo, fosse profissionalmente preparado" (Davis, 1919, p. 7).

Aí está estabelecida uma relação que será reafirmada ao longo do tempo: periódicos de temáticas específicas e grupos profissionais constituídos para o qual os periódicos se destinam. Porém, nem Davis nem os que o antecederam no trato do assunto consideraram o movimento em dupla direção contido na referida relação. São muitos os estudos que indicam, em diferentes países, a especialização e a consolidação de periódicos educacionais como resultantes da conquista de um público leitor definido, estável, também ele especializado. Em contrapartida, esses estudos também evidenciam o caráter processual dessa relação de modo que se pode afirmar, em muitas circunstâncias, que os impressos seriais participaram do processo de profissionalização, portanto especialização, do magistério, processo em que essa profissionalizaçãoespecialização teria operado como uma força positiva no sentido de consolidação da modalidade serial dos impressos, da sua crescente especialização e diferenciação interna (Nóvoa, 1998; Carvalho, 2000, 2005). Esse processo em duplo sentido está para ser devidamente esmiuçado no caso dos periódicos educacionais norte-americanos.

\section{O periodismo educacional norte-americano: do século 19 ao século 20}

Os repositórios consultados indicam que os Estados Unidos se tornaram a pátria do jornalismo educacional, a partir de meados do século 19, ultrapassando de muito a Alemanha, França e Inglaterra nas quais, segundo seus primeiros historiadores (Davis, 1919), teria inteiramente se espelhado até conseguir criar uma fórmula própria.

Foram registrados, nesta pesquisa, 653 títulos sobre os quais foi possível obter, ao menos, o título, o ano de criação ou a cidade/estado da impressão ${ }^{4}$. Excetuando-se Barnard (1865), os demais autores consultados apontam o Academician lançado em 1818 na cidade de Nova York como o primeiro periódico educacional na América com as características especializadas em relação ao teor e ao destinatário. Mesmo efetuando esse corte, praticamente todos os autores parecem ter clareza de que se trata de uma escolha um tanto arbitrária uma vez que entre os subsequentes, também incluídos nas listagens, muitos guardariam as características dos que foram relegados à pré-história do periodismo norte-americano ${ }^{5}$.

Para efeito deste artigo, a lista dos impressos registrados também começa com o Academician, de 1818 e se encerra com o American childhood: the modern magazine for the primary teacher de 1928, que está longe de representar a crescente especialização do conteúdo e fragmentação do público leitor verificada ao longo do tempo.

\footnotetext{
${ }^{4}$ A lista dos 653 títulos com dados completos naqueles itens acima indicados não pode ser aqui apresentada uma vez que ocupa espaço superior ao destinado aos artigos.

${ }^{5}$ Durante a realização da pesquisa que está na base deste artigo, foram localizados ao menos 13 títulos, lançados entre 1774 e 1817, que deveriam ser examinados em maiores detalhes futuramente, de modo a verificar se a sua exclusão da história do periodismo educacional norte-americano não seria um equívoco. Hist. Educ. [Online] Porto Alegre v. 20 n. 48 Jan./abr., 2016 p. $95-120$
} 
Os valores contidos no gráfico abaixo são indicadores da estreita relação entre o crescimento acelerado dos periódicos educacionais nos Estados Unidos, mais de meio século da sua independência, a instalação do regime republicano federalista e os movimentos em defesa da escola pública e gratuita, que se consolidou como um sistema de alcance nacional nas décadas finais do século 19. Assim, a curva traçada pelos impressos aqui registrados pode ser interpretada como correlata do traçado percorrido pela escola pública norte-americana, destacadamente em seus níveis elementares.

Gráfico 1 -

Criação de periódicos educacionais, EUA, 1810-1929, por década.

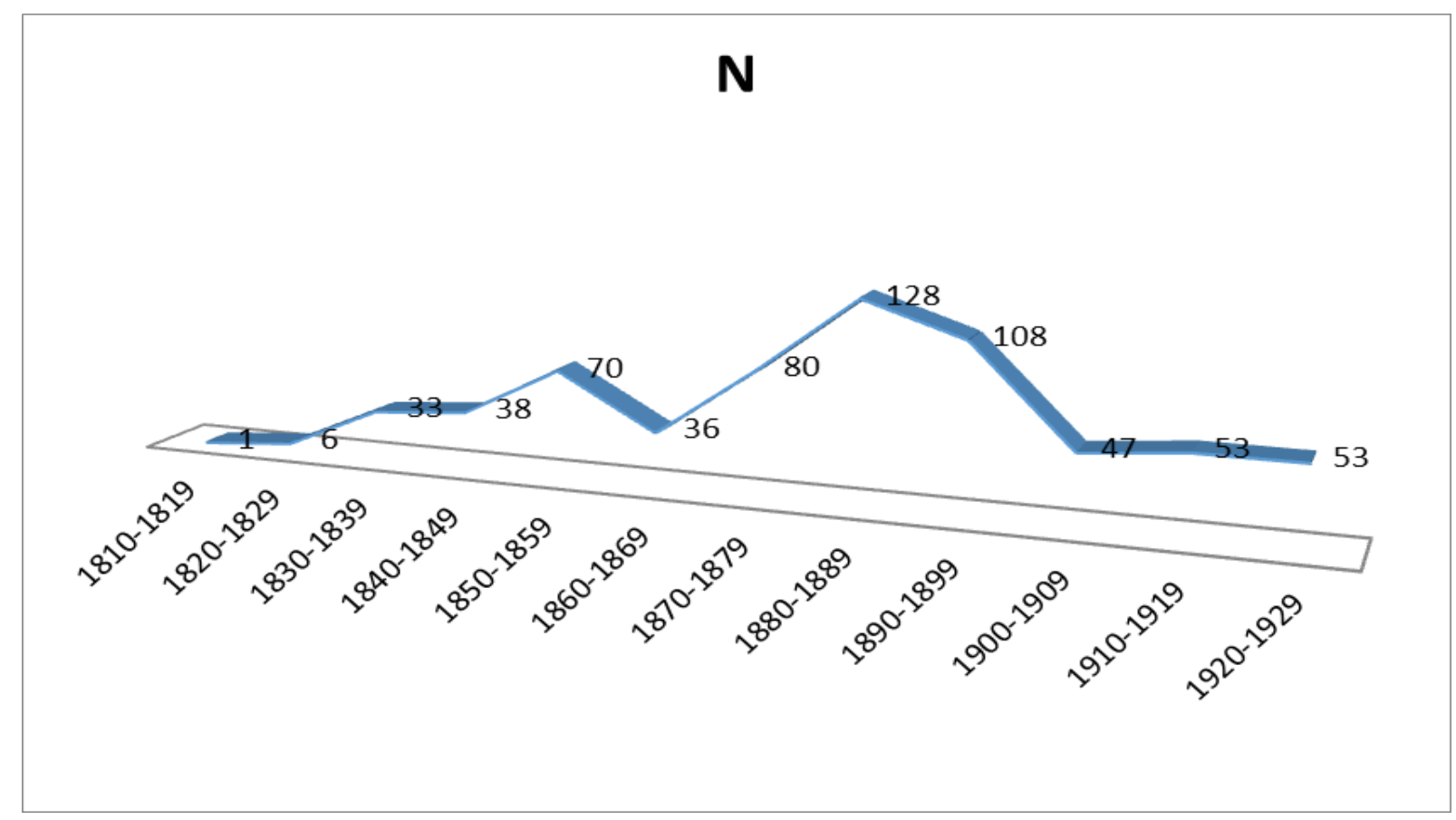

Fonte: Dados coletados em diferentes fontes e organizados por MJW.

Por outro lado, o gráfico representa outras relações ou correlações internas e externas ao sistema de ensino. Destacam-se os intercâmbios culturais alimentados pela importação de impressos, mas, principalmente, pelas imigrações de europeus e pelas viagens de norte-americanos à Europa, a passeio ou a negócio, em maior número a partir de fins do século 18, estimuladas não só pela estabilização econômica que atraía enormes contingentes de imigrantes, como pela busca na Europa, por parte das elites intelectuais e políticas norte-americanas, de subsídios para seus projetos, sociais ou pessoais.

Em meados do século 19 a imigração alemã incluía grandes contingentes de intelectuais, acadêmicos, homens de letras; em larga medida, liberais em matéria política e religiosa, contemporâneos das práticas de comunicação e divulgação por meio de impressos periódicos de destinação escolar. Em suas bagagens: literatura, filosofia, poesia, pedagogia. Para uns tantos norte-americanos Hegel foi dado a conhecer naquele momento; para outros, Herbart; para muitos, Pestalozzi frente e verso. 
No sentido inverso da rota, as marcas da mirada norte-americana rumo à Europa são nítidas nos primeiros periódicos registrados nesta pesquisa: as suas páginas são ocupadas tanto por notícias comezinhas, quanto por notícias educacionais da Alemanha, França e Inglaterra.

O Academician (1818-1820) introduziu Pestalozzi, no mês de janeiro de 1819, em um artigo sobre o seu método de ensino de princípios morais e religiosos, e seguiu lhe dedicando espaço nos meses seguintes em artigos de um anônimo sobre a vida e as doutrinas de Pestalozzi (Monroe, 1907) ${ }^{6}$.

Anos depois, nas páginas do seu American Journal of Education (1826-1830), o editor W. Russell cederia longo espaço para que o já muito proeminente William C. Woodbridge expusesse com fartos detalhes a sua visita a Pestalozzi em 18207 . Em 1929 Russell dava início à publicação das cartas de Pestalozzi a Greaves, traduzindo-as da versão colhida em um periódico francês. Além disso, o AJE de Russell não seria o primeiro e nem o último a preencher suas páginas com a reprodução sistemática de matérias extraídas de jornais franceses e alemães.

Da década de 1830 em diante tornaram-se frequentes, nos ciclos intelectualizados, viagens de visitação e observação à Europa, tal como haviam feito William Russell e William Woodbridge, também eles construtores de narrativas edificantes sobre os alicerces educacionais da civilização europeia. Viajaram Henry Barnard, Calvin E. Stowe, Lowell Mason, Horace Mann, dentre outros. Seus relatos deram muitos frutos, registrados nas páginas dos jornais e nos periódicos educacionais.

Barnard e Mann são dois nomes comumente associados à liderança que exerceram junto às redes escolares em defesa da common school e àquelas viagens de observação à Europa. Muito do que fizeram numa e noutra direção, entretanto, dependeu dos educational journals que editaram como ferramentas eficazes e de relativo sucesso, a considerar os ciclos de vida e o alcance dos seus contemporâneos, para seus empreendimentos. São bastante generosas as passagens do Massachusetts Common School Journal (1939-1952) de H. Mann e dos Journal of the Rhode Island Institute of Instruction (1945-1949) e American Journal of Education (1855-1882) de $\mathrm{H}$. Barnard ${ }^{8}$ reservadas a notícias da educação em países como Alemanha, França e Inglaterra,

\footnotetext{
${ }^{6}$ Muitos autores, como Monroe (1907), localizam as primeiras notícias escritas de Pestalozzi em terras americanas em 1806, nas páginas do jornal National Intelligencer de Washington; no mesmo mês, o jornal teria publicado outras matérias sobre o mesmo assunto. Dois anos mais tarde, Neef (1808) publicou o seu Sketch of a plan and method in education que se tornaria bastante famoso nos meios letrados norteamericanos; sem contar o outro livro de Neef, lançado em 1813, Method of instructing children rationally in the arts of writing and reading. Não tardou o aparecimento de outros materiais impressos sobre Pestalozzi, na forma de livro ou jornais, além dos journals e magazines tratados acima.

7 American Annals of Education, and instruction, and journal of literary institutions (1830-1839), deu seguimento ao AJE de Russel, sob a direção editorial de W. C. Woodbridge. No Annals manteve-se a tradição do antecessor: muitas páginas para notícias da educação no exterior.

8 Os autores norte-americanos referem-se a esse journal como Barnard's American Journal of Education ainda que oficialmente o título não inclua o nome do editor. Foi o modo de distingui-lo dos homônimos de Boston, MA (1826) e de Saint Louis, MO (1868). Neste artigo, as diferentes referências ficarão nítidas entre os dois primeiros; o terceiro não será aqui tratado. Editado pelo col. J. B. Merwin, não obteve reconhecimento e durou três anos.
} 
incluindo seus próprios relatos ${ }^{9}$. Por esses e outros journals, muito além de Pestalozzi, foram dados a conhecer os "grandes nomes da pedagogia europeia", instrumentando a edificação da hagiografia do campo (Bourdieu, 1993).

Depois da Guerra Civil (1861-1865), nas décadas finais do século, outra onda levou norte-americanos aos estudos e observações em instituições europeias: visando ao título de doutor ou de aperfeiçoamento intelectual, estudantes e acadêmicos partiram em busca das inovações científicas que se operavam especialmente na Alemanha e na França, onde se institucionalizavam novos padrões universitários e de pesquisa. A Alemanha foi a meca dos estudantes e estudiosos norte-americanos. Três ou quatro levas de viajantes foram cruciais para modernizar a universidade nos Estados Unidos, preenchê-la de doutores e torná-la instituição de pesquisa. Dessas levas saíram líderes de movimentos reformistas, criadores de agremiações científicas e editores de journals órgãos oficiais ou que funcionavam como tais para aqueles movimentos e agremiações. G. Stanley Hall e seu Pedagogical Seminary (1891-1924) são boas amostras dessas levas de intelectuais viajeiros e seus impressos. Aliás, Hall é também um exemplar de uma liderança reformista. Não o mais radical nem o mais famoso, mas nele estão bem sintetizados os traços acima indicados: reformismo, universidade moderna de pesquisa, associações científicas e impressos.

É sabido que outras viagens transatlânticas estavam ocorrendo desde os anos de 1850 e cujos efeitos difusores para os impressos não podem ser minimamente subestimados no que tange aos Estados Unidos. A título de destaque, as exposições internacionais, serviam de balcões onde eram negociados grandes lotes de livros escolares, periódicos, contratos de tradução e publicação e onde os nomes de autores, editores e casas editoriais norte-americanos eram apresentados ao público estrangeiro (Tebbel, 1975).

A grande onda de viagens à Europa refluiu com a Primeira Guerra Mundial e também com a estabilização do movimento reformista e de modernização institucional norte-americana. E mais uma vez, ocorreu uma grande inversão de rotas, nas quais estavam implicados uma minoria de viajantes temporários em contraposição a uma maioria de imigrantes, muito mais heterogênea quanto à origem geográfica, condição sócio-econômica e nível de escolaridade. Na conjuntura do conflito que viria a tomar proporções mundiais, os esforços de guerra implicaram na canalização de recursos materiais e humanos em detrimento de indústrias de ramos como a dos impressos.

Essa conjuntura bélica foi poderosa, mas não explica sozinha a queda vertiginosa dos lançamentos de novos periódicos educacionais. Outros fatos devem ser buscados para o entendimento de uma queda não só brusca como também continuada de, ao menos, trinta anos.

\section{Geografia do educational journalism}

Os polos norte-americanos mais intelectualizados, culturalmente mais sofisticados, com alta confluência de universidades, museus e demais instituições artísticas e acadêmicas concentraram, desde final da Guerra Civil, o maior número de indústrias modernas e de regiões de acelerada urbanização. Esses polos são aqueles que

\footnotetext{
${ }^{9}$ Isso para não falar de outros impressos nos quais Mann e Barnard se destacaram sobremaneira. 
estiveram, décadas antes, na vanguarda dos movimentos em favor da escola comum, pública, gratuita. Foi neles que, não casualmente, os parques gráficos e os mercados editoriais também se concentraram (Tebbel, 1975; Warde, 2011).

Não só do ponto de vista das características culturais, mas também das concentrações populacionais, pode-se entender a distribuição geográfica dos periódicos educacionais lançados de começo do século 19 a começos do século 20. Naqueles mais de cem anos o mapa de ocupação do que se constituía como os Estados Unidos da América se alteraram grandemente: até a segunda metade do século 19 a população norte-americana estava praticamente toda concentrada no lado atlântico. Da Guerra Civil resultou não só a hegemonia do Norte/Nordeste sobre o Sul, e os consequentes processos de urbanização dessa região, como implicou o alargamento das fronteiras rumo ao Oeste que, por diversos fatores, nunca gerou concentração populacional equivalente ao outro lado do vasto território, a não ser na Costa Pacífica, a Califórnia, de alta densidade demográfica.

As maiores afluências de periódicos educacionais nos Estados de New York $(12,86 \%)$, Massachusetts $(9,19)$, Illinois $(9,04)$, Pennsylvania $(7,04)$ e Ohio $(6,13 \%)$ derivam dessa concentração humana, assim como representam um agregado de fatores muito favoráveis ao domínio das letras em geral e à escolarização em particular.

Em cada um desses Estados algumas cidades funcionaram como epicentros culturais dinâmicos e irradiadores de códigos de comportamento e padrões de institucionalização dos procedimentos, mas principalmente de produção de inovações que iam se impondo como necessárias em decorrência da partilha dos mesmos códigos e padrões. No topo a cidade de Nova York, responsável pelo lançamento de 49 dos títulos dos quais se pode conferir o local de produção. Compondo com Syracuse (9) e Albany (6), além de algumas outras cidades, a cidade de Nova York fez do Estado homônimo o epicentro da indústria e do mercado de impressos educacionais. Segue-se, na mesma região Nordeste dos Estados Unidos, Boston, no Estado de Massachusetts, responsável por 38 títulos, acompanhada de longe por Springfield (8) e Worcester (6). Embora vinda de mais longa tradição intelectual e acadêmica, Massachusetts não acompanhou no mesmo ritmo e intensidade a modernização urbana e industrial novaiorquina. Ainda na mesma região, Philadelphia (46) e Pittsburg (6) no Estado da Pennsylvania.

Despontaram ao término da Guerra Civil, os Estados do Centro-Oeste e suas novas ocupações populacionais resultantes de migração e de densas levas imigratórias. Para Estados da região acorreram os grandes contingentes de alemães e seguidos, a uma certa distância, por irlandeses, escandinavos e eslavos. Com isso o Centro-Oeste constituiu um outro polo de modernização, mas sem a opulência, a transgressão e as pretensões hegemônicas dos Estados anteriormente referidos. Nessa segunda região estão Illinois, mais ao centro, tendo Chicago por epicentro de onde foram lançados 37 periódicos educacionais no período. Com características bem mais provincianas, Ohio, na mesma região impulsionada pela imigração europeia, lançou 40 periódicos, dos quais 15 na cidade de Cincinnati e 13 na de Columbus.

Mas para o que e para quem esses periódicos eram lançados? Com que finalidades e na expectativa de produzir que efeitos? As respostas a essas perguntas devem permitir outras inferências mais sutis sobre os impressos e suas relações com os sistemas de ensino e os ambientes culturais correspondentes. 


\section{Quem respondia pelos periódicos educacionais}

Da maioria dos periódicos estudados sabe-se ao menos os nomes dos editores $(68,6 \%)$. Em alguns casos os próprios proprietários das casas editoriais respondiam pela publicação e pela editoria, como os Kellog, responsáveis por muitos títulos. Na quase totalidade dos casos em que o editor é um indivíduo não é dado a saber quando se trata de pessoa ligada ao mercado editorial ou aos sistemas de ensino. Os indícios reunidos sugerem que dentre esses editores havia muitos diretores em exercício ou aposentados. Pouco se sabe sobre a maioria deles, a não ser que tenham exercido funções em instâncias superiores como, por exemplo, superintendência de ensino e participação em conselho de educação - board of education -, mesmo quando essas funções tenham sido exercidas em pequenos munícipios - os counties. O mesmo se passa com o professor de college ou de universidade cujo posto, em regra, acompanha o nome. Indicadores razoavelmente nítidos de status e de algum poder nas hierarquias educacionais e do mercado editorial.

Dentre dirigentes e lideranças do ensino, vale destacar nomes que se projetaram no século 19 antes da Guerra Civil (1861-1865): William C. Woodbridge, William Russell, Horace Mann, Henry Barnard e Norman A. Calkins. A partir deste conflito, dentre os que se sobressaíram na universidade e no ambiente acadêmico, despontam nomes como: G. S. Hall, Isaac Kandel, Nicholas Murray Butler e Charles H. Judd. Há entre esses dois grupos diferenças significativas quanto às condições financeiras e editoriais. $\mathrm{O}$ primeiro grupo compunha uma tendência dos empreendedores individuais que, sem grandes recursos financeiros, no início, costumavam sair da empreitada com menos ainda. Seus esforços destinavam-se a uma causa: os periódicos eram seus palanques. Essa geração tendeu a ser substituída pelas iniciativas de agremiações educacionais ou casas editoriais. Em ambos os casos as chances de sobrevivência cresceram, sobremaneira, para além daqueles um ou dois anos dos primeiros tempos.

As iniciativas associativas tenderam a crescer, a partir da década de 1850, quando os impressos seriais passaram a funcionar como instrumentos de comunicação de dirigentes, professores e funcionários escolares. Mais tarde os periódicos seriam projetados para funcionar como veículos de troca e de informação científica entre pares. Mesmo quando mantida a responsabilidade de um único editor, as associações de professores, em primeiro lugar, e demais modalidades associativas vinculadas ao Estado - tais como associações de superintendentes e diretores - ou às denominações religiosas, às igrejas, aos movimentos pedagógicos - tais como as uniões de escolas dominicais, as sociedades de escolas católicas, as pestalozzianas e as herbartianas -, ou ainda, as universidades, sociedades científicas, academias - cresceram em ritmo constante até se tornarem responsáveis pela quase totalidade dos periódicos na década de 1920 .

Sobre esses deslocamentos, diz Dunkel (1975, p. 391) que, no começo do século 19 ,

a maioria dos jornais educacionais tinha sido empreendimento de empresários particulares que procuravam um modesto sustento e um lugar para expressar suas opiniões. Como Henry Barnard registrava periodicamente no melancólico placar do seu American Journal of Education, a maioria dessas empresas pereceu dentro de um ou dois anos. Ocasionalmente, alguém como Barnard ou William T. Harris, com o 
seu Journal of Speculative Philosophy, destinaria sua renda pessoal extraída de outras fontes para manter seu jornal vivo mesmo com perda constante. Nas décadas finais do século, as revistas (journals) financeiramente mais seguras e, portanto, de mais longa duração tendiam a ser aquelas conectadas com a uma casa editorial. Matérias publicadas em séries nas revistas (journals) podiam ser reimpressas na forma de livro, e a revista podia ser usada como um meio de propaganda para outras mercadorias da firma. A Kellog de Boston, a Bardeen de Syracusee a Brown de Bloomington, Illinois, são excelentes exemplos de editores desse tipo. O aumento das "state educational associations" com suas amplas e sólidas listas de assinantes também produziu novas revistas (journals) ou assumiu o controle de mais antigas.

Nos anos sessenta do século 19, Barnard (1865, p. 383) havia localizado 20 revistas lançadas entre 1838 e 1864 como "órgãos de associações estaduais de professores". Décadas depois, a lista de Davis (1919) apresenta pequena variação: 23 revistas criadas entre os anos de 1841 e 1872 mantidos por aquela modalidade específica de agremiação.

Outras associações não cessaram de aparecer em diferentes localidades, ganhando uma certa regularidade com as state teachers' associations nascidas a meados do século 19 (Alexander, 1910; Foos, 1909). Kirk (1883) apresenta uma lista de 41 associações existentes à época em todo país, com talvez uma ou duas exceções de Estados ou territórios, a maioria surgida entre os anos de 1850 e 1870, com redução decorrente da guerra civil.

Davis (1919) chama a atenção para o fato de que essas são revistas muito parecidas ou que vão ficando muito parecidas com o tempo, na medida em que as próprias associações se tornam mais e mais semelhantes. Em todas há registros de tensões nas quais aparecem em campos opostos os editores e os associados, os homens e as mulheres, os defensores do ensino laico e os a favor do ensino religioso, para citar alguns exemplos. Mas o mais persistente mesmo é o problema do sustento financeiro. A tendência de as states teachers' associations assumirem as revistas, financeira e editorialmente, foi, em geral, positiva, mas só uma combinação feliz de circunstâncias e uma administração competente as salvava de fracasso.

O jornalismo educacional de meados do século 19 foi também afetado pelas tensões entre as tendências localistas e universalistas. Superintendentes de ensino em nível estadual, em regra, estimulavam o orgulho localista apelando para o nome dos Estados nos títulos dos jornais, comparando-os a outros Estados que faziam o mesmo. Porém, contraditoriamente, fechados nos interesses locais, os periódicos tinham menos chances de sobreviver, especialmente em regiões pequenas. Assim, o alargamento dos seus temas acabava por alargar as fronteiras geográficas para sua circulação. Em meados do século 19 incrementou-se o debate em torno do alargamento do escopo das revistas e da extensão do raio de circulação. Exemplos, a New Jersey State Teachers' Association, por exemplo, adota a New York Teacher como seu órgão oficial; o New England Journal of Education de 1875 resulta da associação de vários periódicos, todos órgãos de state teachers' association; o Educational Weekly, estabelecido em Chicago em 1877, une-se a journals de diferentes Estados. Passado um tempo, tanto o primeiro quanto o terceiro voltam a ser locais. Outros periódicos sofreram as mesmas dificuldades para se manter abrangentes, com inclusão de análises e informações de outras regiões, uma vez que na 
contramão da tendência universalista grassava, na segunda metade do século, a tendência localista que buscava mais especialização "para responder às necessidades locais" (Davis, 1919, p. 42).

Davis (1919, p. 44) localizou 281 "county school journals" de "antes de 1865" a 1899. Desses, $256(91,1 \%)$ foram criados entre 1880 a 1899, sendo que no último quinquênio (1895-1899), a frequência já estava consideravelmente reduzida. Nos anos de 1890 uma nova tendência começou a surgir nos Estados Unidos: cadeiras e departamentos de Pedagogia ou de Educação estavam sendo criados nas universidades, como resultado dos esforços para transformar a educação num campo de estudos acadêmicos. Esses esforços conduziram, também, à publicação de journals de níveis crescentemente mais elaborados e padrões editoriais mais exigentes, tais como: o Pedagogical Seminary (1891-1924, na primeira fase); o Educational Review (1891-1928); o School Review (1893-1979) e o Teachers College Record (1900-) entre muitos outros posteriores.

\section{Para o que e para quem esses periódicos eram lançados? Com que finalidades e na expectativa de produzir que efeitos?}

A preferência de Davis (1919) pela expressão school journal tem razão de ser considerando-se o século 19, alvo da sua pesquisa. Deixemos de lado o termo journal em contraposição a magazine ou qualquer outra palavra - e pensemos na específica destinação escolar. A quase totalidade dos periódicos lançados naquele século destinavase, de fato, aos professores do ensino elementar, em primeiro lugar, seguidos a certa distância dos professores secundários, depois aos funcionários, administradores, dirigentes escolares em diferentes instâncias conforme foram se estabelecendo, crescendo em número e se especializando. A prevalência das associações profissionais entre os editores coletivos, entre as décadas de 1870 e 1890, aponta para esses públicos leitores. O público universitário só ganhou presença significativa durante o século 20.

Os periódicos iniciais como Academician, Teacher's Guide and Parent's Assistant, American Journal of Education/, American Annals of Education, and instruction, and journal of literary institutions constituem iniciativas corajosas. A incipiência da escola comum e a fluía exigência técnico-profissional do magistério - em contraposição à alta demanda de testemunhos morais e religiosos -, somadas à baixa gerência ou ingerência do Estado em assuntos educacionais explicam, de um lado, o reduzido investimento em impressos especializados e, de outro, elucidam o interesse de algumas figuras públicas na utilização do impresso como um instrumento de comunicação e informação - tal como algumas dessas figuras tinham visto acontecer em países como Alemanha e França, onde os impressos periódicos funcionavam como elo de comunicação, instrumento de modelação profissional, veículo de normatização e normalização. Figuras públicas como os Pickett, S. G. Goodrich, W. Russell, W. C. Woodbridge que, observando direta ou indiretamente as novas tendências de publicização e pedagogização do ensino em curso na Europa, projetaram os seus periódicos para funcionarem como cadeias de transmissão das suas posições políticas e pedagógicas.

O Academician, periódico quinzenal de New York, durou de 1818 a 1820, editado por Albert e John W. Pickett, presidente e secretário respectivamente da Incorporated Society of New York Teachers, foi uma das primeiras importantes iniciativas no periodismo educacional dos Estados Unidos. Com esse impresso os Pickett pretendiam 
ofertar, como afirma o subtítulo do periódico, "elementos da ciência escolástica e os contornos da filosofia da educação baseados nas análises da mente humana e apresentar os melhores métodos da instrução" (Davis, 1919, p. 11).

Os Picketts eram diretamente envolvidos em assuntos escolares: proprietários de uma escola na cidade de Nova York e autores de livros didáticos concediam a esse assunto destacado espaço no magazine. Acrescentavam um amplo leque de temas, sendo uma parcela dedicada à gramática e à língua inglesa, bem como a longas discussões de Aritmética e Geografia ${ }^{10}$, escolas monitoriais e resenha de livros. Muitas páginas do Academician são dedicadas ao trabalho de Pestalozzi, mas o que chama especial atenção é a grande quantidade de longas matérias reproduzidas de jornais alemães e franceses. Com isso, esse impresso se situa no início de um longo processo de familiarização do leitor norte-americano às grandezas do ensino alemão e francês nos quais os Estados Unidos deviam, segundo eles, se espelhar.

O American Journal of Education (1826-1830) foi outra importante iniciativa que se seguiu, editado por William Russell ${ }^{11}$, e continuado pelo American Annals of Education (1830-1839) que seria de responsabilidade editorial de W. C. Woodbridge. A ele, outros periódicos dedicaram páginas elogiosas. No mesmo ano do seu lançamento, The North American Review (1826, XXIII, p. 214-215) Ihe reserva uma resenha de pouco mais de duas páginas:

A recepção do AJE foi muito boa. Quando esse mensário foi lançado, havia não poucos [...] que consideravam o tema da educação muito específico e muito delimitado para fornecer material para um "journal" de tamanho grande e de longa duração. Mas se suas reflexões não os convenceram do erro, um exame desse valioso trabalho os convencerá que $o$ assunto oferece materiais de grande variedade e profundo interesse para a comunidade. $O$ que quer que tenda a formar uma mente sã em corpo são, ou, em outras palavras, a erigir o homem mais perfeito física, intelectual e moralmente, está dentro dos limites de suas indagações. $O$ tema da educação não era efetivamente negligenciado nos nossos respeitáveis "journals" que existiam previamente, mas há uma vasta quantidade de informação sobre ela que não pode ser incorporada em qualquer um, senão em todos eles.

Ao periódico de Russell, Barnard (1851a) destinaria elogiosa avaliação na sua obra sobre a educação dos professores nos Estados Unidos. No tópico reservado ao Estado de Massachusetts, ele diz:

Embora o estado não tenha concedido auxílio a qualquer "educational journal", um ou dois têm sido publicados no estado desde 1826. [...] Em $1^{\circ}$ de janeiro de 1826 começou o primeiro número do American Journal of Education, o primeiro periódico dedicado ao assunto, que apareceu em língua inglesa, e o Annals of Education, sob cujo nome foi publicado depois de 1830, continuou até 1839. Mês após mês, ano após ano, esse periódico

${ }^{10}$ O Academician foi precursor na criação de um departamento dedicado a assuntos de Matemática, no que seria seguido pela maioria dos jornais escolares do século 19 (Davis, 1919).

11 Este American Journal of Education foi editado entre 1826 e 1830 por William Russell (nascido em Glasgow, Escócia, em 1798, e falecido em Lancaster, Massachusetts, em 1873) que se tornou proeminente educador nos EUA. Para dele se distinguir, o seu homônimo de 1855 a 1881, costuma ser registrado como Barnard's American Journal of Education. 
habilmente conduzido espalhou, diante de um número limitado de mentes, visões mais amplas e mais generosas da educação - sua natureza, objeto e métodos - do que tinha sido até então oferecido. (Barnard, 1851a, p. 232)

As pretensões de Russell, de fato, não eram pequenas. Queria fazer do seu $A J E$ "um registro dos fatos" do passado e do presente da educação "nos Estados Unidos e nos países estrangeiros para que possa proporcionar uma justa comparação dos méritos de vários sistemas de instrução" (American Journal of Education, 1826, p. 2). O carro chefe da revista, no entanto, seria a "primeira e elementar educação porque é, em nossa opinião, mais importante do que aquela de qualquer outro período". Ao mesmo tempo, diz o editor, "não devemos omitir os ramos mais altos da ciência e da literatura, nem a formação preparatória para as atividades profissionais" (p. 3). Especialmente interessante é o destaque conferido pelo editor ao tópico da "educação feminina" pouco frequente nos demais periódicos; nós o julgamos, diz ele, "indizivelmente importante" (p. 3), a ponto de merecer a atenção superior aos demais.

No mesmo ano foi lançado o Teacher's Guide and Parents' Assistant (Boston, 18261828), que resultou de um projeto menos pretencioso do que o de Russell. Samuel G. Goodrich, o editor, conferia mais atenção aos livros para as crianças e aos problemas enfrentados por pais na educação dos filhos, como o próprio título indica. Pensando especialmente no professor, esse impresso - que variou de mensal a bimestral propagandeava a pedagogia de Pestalozzi, principalmente por meio da descrição do método de seu seguidor Joseph Neef (1770-1854) ${ }^{12}$.

Dez anos depois foi lançado o Common School Assistant (1836-1840), inicialmente em Albany e depois em Nova York, no mesmo Estado. O CSA manteve a prática de reprodução de documentos inteiros, ainda que implicando no uso de um e às vezes mais números para esse fim. Isso ocorreu, por exemplo, com os relatórios de Victor Cousin. Entretanto, o periódico marcou presença entre os impressos escolares do Estado de Nova York, destacadamente pela divulgação de métodos e aparatos tidos como inovadores não só para as pequenas localidades.

Esses impressos representam bem os primeiros periódicos educacionais norteamericanos. Mantinham algumas características comuns, além dos curtos ciclos de vida: davam farta divulgação à pedagogia de Pestalozzi e promoviam relatórios como os de Cousin, reproduzidos em quase todos os periódicos norte-americanos; defendiam a importância da educação e a necessidade de free schools para a construção da República. Dos 20 e poucos periódicos educacionais estabelecidos antes de 1840, muitos se referem aos periódicos publicados na Alemanha e na França como exemplos e tudo indica que pretendiam funcionar em relação aos professores como entendiam ocorrer naqueles países em que os comandos e as orientações chegavam às escolas pela via dos impressos seriais.

\footnotetext{
${ }^{12}$ Seu sobrenome é, originalmente, Näef como se usava na Alsácia, França. Uma característica interessante dessa publicação é o grande número de pequenos artigos sobre temas educacionais citados de jornais locais ocupando a maior parte das suas páginas, o que levou ao comentário do AJE de que os jornais de várias partes do país estavam prestando atenção neste importante assunto para o bem estar da comunidade indicando "progresso da mente pública" (American Journal of Education, 1826, p. 2). Aparentemente, não havia restrições às mútuas citações e referências; ao contrário, tudo indica que os jornais e revistas se beneficiavam dessa propaganda gratuita. 
Os periódicos cresceram em número, mas poucos davam contribuições originais ao campo da educação e impactavam significativamente o ramo. Duravam pouco e a circulação era bastante reduzida. Alguns se destacavam com muito esforço, como o Connecticut Common School Journal (Hartford, CT, 1838-1866), editado por Henry Barnard como órgão do Board of Comissioners of Common Schools, do qual era então o segundo secretário. Apesar de não ter ganhado destaque nos primeiros anos, o periódico se fez relevante ao longo do tempo, na medida em que se estabilizou como veículo de divulgação das políticas educacionais e das proposições pedagógicas do Connecticut.

No Prospectus que abre o primeiro número do CCSJ, o Conselho diz que o objetivo seria o de

promover [...] a prosperidade crescente e a extensa utilidade das escolas comuns de Connecticut. Será empregado em conexão com os impressos públicos, como um órgão de comunicação entre o Conselho e seu Secretário, e o público. Conterá as leis do estado no que se refere às escolas comuns. Apoiará os comitês escolares e os inspetores escolares no cumprimento das suas obrigações. Ajudará a formar, encorajar e fazer avançar bons professores, Fornecerá matéria adaptado à capacidade das crianças em nossas escolas, para sua instrução e divertimento racional. Será um dos meios de averiguação das verdadeiras deficiências que possam existir nas escolas, e de sugerir adequadas soluções. Visará fornecer informação sobre o que está sendo feito em outros estados, e em outros países em relação à educação popular. (Connecticut Common School Journal, 1838, I, p. 5)

Barnard editou o CCSJ até 1842. Em 1845, foi nomeado "comissioner of public schools" em Rhode Island onde, em seguida, Iançou The Journal of the Rhode Island Institute of Instruction até 1848 - o ciclo de vida do periódico foi de 1845 a 1849. Barnard retornou a Connecticut em 1849 para servir como superintendente das escolas comuns. À testa dessas escolas ressucitou sua primeira publicação e a editou de 1850 a 1853 . Em muitos aspectos, segundo Mclnerny (1989), o CCSJ prefigurou a experiência que Barnard teria como o seu mais famoso American Journal of Education (Monroe, 1893)

A política editorial adotada por Barnard no mensário de Connecticut centrava-se no apoio à escola pública, seja pela documentação oficial, seja por artigos relativos a ela, ainda que, assim, seu público leitor permanecesse reduzido. Curiosamente, Barnard "se convenceu de que as revistas educacionais estavam entre as melhores agências de avanço educacional, pois estavam auxiliando na obtenção e divulgação da melhoria na educação" (Thursfield, 1945, p. 21). Porém, essa descoberta não o auxiliou a desenvolver uma política de financiamento dos seus empreendimentos impressos. Seus historiadores informam que Barnard teria sido um dos primeiros editores a adotar o pagamento de autores para escreverem artigos específicos para seu journal, uma prática editorialmente arrojada, mas um tanto prejudicial aos bolsos do próprio Barnard que era o responsável pelo pagamento dos custos do impresso que editava, apesar de ser o órgão oficial do state board. Barnard teria tirado do próprio bolso $\$ 1,800$ para manter a revista funcionando nos três primeiros anos, dos quais mais de $\$ 400$ teriam se destinado ao pagamento por artigos encomendados (Thursfield, 1945; Mclnerny, 1989). 
Na mesma linha dos periódicos de destaque à época, o Common School Journal (Boston, 1838-1852) marcou presença por apresentar as inovações escolares de Horace Mann, seu editor e então Secretary of Board of Education de Massachusetts.

Mann soube fazer do CSJ um veículo de comunicação vertical em torno do sistema escolar que estava então sendo estabelecido. Por esse meio estimulou os professores a responder perguntas, comentar os problemas e a consultar lições de Geografia, Ortografia entre outras matérias, criando uma tradição que seria seguida por revistas mundo a fora. (Good, Teller, 1969; Tharp, 1953). Para alimentar a sessão, Mann respondia pessoalmente a correspondência.

No Prospectus do CSJ (1838, I, p. 1) o leitor é informado que

o grande objetivo do trabalho será o aperfeiçoamento das escolas comuns, e outros meios da educação popular. Pretende-se também fazê-lo um depositário das leis do Commonwealth ${ }^{13}$ em relação às escolas, e dos relatórios, anais etc. do Massachusetts Board of Education. Como os documentos do conselho terão um interesse geral, eles deverão ser amplamente difundidos e permanentemente preservados. A revista explicará, e, até onde for possível, reforçará para todos os pais, guardiões, professores e funcionários escolares, suas respectivas obrigações com a geração em crescimento. Serão também endereçados às crianças e jovens todos os motivos intelegíveis para obedecer as leis da saúde física, para cultivar o "bom compartamento", fortalecer as faculdades intelectuais e enriquecê-las com conhecimento; e aperfeiçoar sentimentos religiosos e morais no domínio e controle dos animais e propensões egoístas. A revista se manterá inteiramente afastada de partidarismo político e sectarismo religioso [...] Não será somente objetivo do trabalho descobrir, mas difundir conhecimento. Nesta época e neste país, a dificuldade não é tanta; porém poucas coisas sobre o tema da educação são sabidas; assim, poucas pessoas as conhecem.

Embora bastante inovador, Mann também publicaria, como fizeram seus antecessores, extensos relatórios sobre suas visitas às escolas alemãs e relatórios anuais emitidos no exercício da sua função junto ao Board of Education: "A revista forneceu um meio para ele argumentar em favor da escola comum, em favor da educação das crianças imigrantes e outras importantes questões" (Mclnerny, 1989, p. 22).

Publicando-se fartamente no CSJ, Mann tornou-se seu principal colaborador. Sua esposa Mary Peabody ${ }^{14}$ também contribuiu com vários artigos, alguns sobre lições de Geografia e de Desenho publicados em partes e com muitas ilustrações. Segundo Tharp

13 "O termo Commonwealt é uma nomenclatura utilizada por quatro dos estados constituintes dos Estados Unidos da América em seus nomes oficiais e completos. Esses Estados são Kentucky, Massachusetts, Pennsylvania e Virginia. Os quatro estão entre os 15 primeiros Estados a aderir à União. Essa designação, que não tem qualquer significado jurídico, enfatiza que eles têm um "governo com base no consentimento mútuo entre as pessoas" - http://en.wikipedia.org/wiki/Commonwealth \%28U.S. state $\% 29$.

14 Mary Tyler Peabody Mann, esposa de Horace Mann, era irmã mais nova de Elizabeth Palmer Peabody que também se tornou famosa como educadora e reformista. A instalação do primeiro kindergarten em língua inglesa nos Estados Unidos. Foi sua intervenção de maior repercussão dentro e fora do país; seu nome se consolidou com a criação e edição do periódico Kindergarten Messenger em 1873 (Tharp, 1953). Ver, neste dossiê, o artigo de Carla Chamon sobre a entrada do kindergarten nos Estados Unidos.
Hist. Educ. [Online]
Porto Alegre
v. 20
n. 48
Jan./abr., 2016
p. $95-120$ 
(1953), Mann soube utilizar plenamente e de maneira original o impresso, não só com lições, mas também com o humor e a sátira. Para Davis (1919), nenhum outro tinha se revelado até então tão bom editor quanto Mann.

Ainda que bom editor, Mann não escapou das mazelas financeiras comuns aos seus contemporâneos editores: como outros, emprestou dinheiro pessoal à editora do CSJ que jamais o ressarciu. Mann também não escapou das dificuldades de dar aos professores acesso às páginas do CSJ, comprometido com a causa da escola pública comum e gratuita. Segundo Davis (1919), a revista de Mann alcançou menos os professores das escolas públicas do que aos docentes das escolas particulares e aos clérigos.

Em 1848, quando findou sua função de secretário do Massachusetts Boad of Education, Mann escreveu o último artigo para o CSJ e deixou também a função de editor, sendo substituído por William B. Fowle que o manteve até 1852 (Tharp, 1953; Davis, 1919; Mclnerny, 1989).

Apesar de curta duração, merecem referência também o Journal of Education de Michigan (Detroit, MI, 1838-1840) editado pelo superintendente do ensino, J. D. Pierce, conhecido como "pai do sistema público de ensino de Michigan" (Davis, 1919, p. 23), e o Ohio Common School Director, editado por Samuel Lewis, por terem sido os primeiros periódicos do Centro-Oeste sustentados com dotação da Assembléia Legislativa de seus respectivos estados. Alguns historiadores, como Davis (1919), têm por hipótese que o uso desse meio para o incremento da educação pública teria vindo da leitura do relatório de Cousin sobre a educação na Prússia, no qual informa que alguma literatura profissional era anualmente enviada aos professores prussianos a expensas do estado.

De vida bem mais prolongada, o District School Journal for the State of New York (Geneva/Albany, NY, 1840-1852), editado por Francis Dwight, cita os predecessores de Michigan, Connecticut e Massachasuttes como motivos para aspirar à condição de órgão do Estado. Eles, diz o editor do DSJ (1840, I, p. 2), são conduzidos por funcionários que conhecem o assunto e se destinam à comunicação entre todos os envolvidos com o ensino, bem como com os habitantes dos distritos, suas matérias são de interesse de todos.

O American Journal of Education (1855-1881), editado por Henry Barnard, foi o primeiro a ganhar alcance nacional e internacional. Na Exposição de Paris de 1878 foi agraciado com uma medalha de ouro que alçou o nome de Barnard no altar dos grandes educadores. A ideia original do editor, desde que passara a criar periódicos como ferramenta para construção de sistemas públicos de ensino, era a de fazer do seu AJE uma enciclopédia de educação. Não tinha expectativa de torná-lo popular, apostava mais da qualificação dos agentes escolares do que nas lições facilitadoras (American Journal of 
Education, I e 19) ${ }^{15}$. Para isso, pretendeu pô-los em contato com informações sobre a educação pelo mundo. Assim como faria nos relatórios do United States Commissioner of Education $^{16}$, reproduzidos como artigos extensos sobre educação na Argélia, Ceilão, Dinamarca, Grécia, Holanda, Islândia, Itália, México, Noruega, Rússia, Suécia e países da América do Sul.

Barnard adotou um estilo novo: reservou volumes inteiros a um aspecto específico da educação. A título de exemplo, o 18 e o 19 são dedicados às estatísticas gerais e educacionais. No conjunto, o AJE representa um esforço sistemático de produzir certa concepção da educação, difundir certo modo de entendimento do passado, sedimentar uma determinada memória da educação; padronizar uma hierarquia de grandes nomes, dos maiores e melhores sistemas educacionais no mundo; oferecer um cânone do que é certo e do que é errado nas práticas escolares. Essas intenções se expressam no grande número de matérias de história da educação, biografias educacionais, ensinamentos teóricos dos grandes homens desde os gregos aos contemporâneos, descrição de sistemas e de práticas escolares de outros países. Atravessando todos esses assuntos, muitas traduções do alemão.

A ênfase nos estudos históricos da educação é muito maior do que a que se obtém pela medida do espaço ocupado. Para quase toda instituição ou movimento educacional é considerado o seu desenvolvimento histórico. Por exemplo, um apanhado abrangente de todas as associações estaduais de professores é dado, discutindo sua origem, crescimento e atual condição, um apanhado semelhante das escolas normais ocupa $1 / 4$ do volume 17. Discussões de educação estrangeira, frequentemente, históricas, ocupam $1 / 4$ de todo o espaço nessa série: alemã, britânica e francesa lideram nessa ordem, mas Holanda, Canada, Sardenha, Noruega, Suécia, Bélgica e Grécia, tanto quanto países menos importantes, comparecem. Esses estudos derivam seu verdadeiro valor do fato de serem comumente traduções de trabalhos-padrão ou de relatórios oficiais. Relatórios de visitantes oficiais designados para estudar vários sistemas nacionais de educação, tais como o de, mais uma vez, Cousin, Stowe, e Bache, ganham muita atenção (American Journal of Education, vols. VII e IX). Cada fase da educação em países estrangeiros era tratada de modo abrangente pela publicação no mesmo ou em volumes sucessivos de todo material que se pudesse coletar de todos os países sobre os quais se trata do assunto em discussão, assim, rendendo comparações possíveis. Exemplos que podem

\footnotetext{
${ }^{15} \mathrm{Em}$ 1850, Barnard se esforçou para interessar a American Association for the Advancement of Education em seu plano de criar uma agência central para difusão do conhecimento, parte do qual seria a publicação de um jornal e uma biblioteca de educação. Barnard não contava com fundos para isso a AAAE e a Smithsonian Institution, a qual ele também recorreu, não se dispuseram a bancar o projeto integralmente. Barnard assumiu a empreitada ele mesmo; juntou-se ao Rev. Absalom Peters que tinha similar propósito e juntos lançaram o American Journal of Education and College Review. Logo descobriram que não podiam continuar juntos, e Barnard voltou ao nome original: American Journal of Education. Em 1860, no v. VIII, curiosamente Barnard confessa ter descoberto que professores - do ensino médio ou elementar - ou administradores dos sistemas municipais e estaduais, ou os defensores confessos da educação popular não se disporiam a fazer sacrifício pela revista, subscrevendo-a ou trabalhando por ela (Davis, 1919). Em Bardeen (1881) encontra-se um relato das dificuldades enfrentadas por Barnard quando se associou ao Rev. Peters, bem como as tentativas de Miss Peabody, cunhada de Horace Mann, de salvar a revista de Barnard.

${ }^{16}$ Em 1867 Henry Barnard foi eleito o primeiro United States Comissioner of Education. Em 1870, o Comgresso converteu o órgão de departamento em bureau, reduzindo seu alcance e funções. Barnard, então, se demitiu.
} 
ser notados são: o tratamento dos deficientes (American Journal of Education, III e IV); escolas técnicas (American Journal of Education, VII e X); escolas navais e militares (American Journal of Education, XII e XIV); universidades (American Journal of Education, XXIV, XXV, XXVII e XXVIII) (Davis, 1919)

Para Ackerman (1968), a editoria do AJE foi a mais substancial contribuição de Barnard para a literatura educacional. O caráter abrangente do periódico - que tratava da pré-escola à universidade, dos meninos rebeldes aos estudantes do ensino superior teria conferido coesão aos esforços que estavam sendo feitos em educação por todo o país.

Com o AJE, Barnard teria se dado a grande oportunidade de avançar na cruzada pelas escolas comuns em bases nacionais, veiculando os meios para implementá-las e torná-las aceitas como parte da sociedade americana. Seus relatórios refletem o interesse pela educação pública nos seus vários aspectos: do currículo à apropriada ventilação da sala de aula. Barnard abordou, em impressos diversos, assuntos como métodos de ensino, arquitetura escolar e muitos outros. Mas sua ênfase sempre foi a formação do professor, sem a qual, ele sabia, não haveria projeto escolar vitorioso. Pelas páginas do $A J E$, ele manteve a luta pela difusão das escolas normais e dos institutos docentes (Barnard, 1851a, 1851b).

Foram 32 volumes e 24.000 páginas. O mais monumental produto de Barnard que o envolveu entre 1855 e 1881. Nele estaria refletida a mudança conceitual em educação nos Estados Unidos desse período e dos seguintes, para os quais o AJE teria contribuído no estabelecimento de novos padrões (Thursfield, 1945).

O AJE de Barnard talvez tenha sido o mais exitoso e o último dos periódicos enciclopédicos a obterem alcance nacional e internacional. Depois da Guerra Civil e antes da virada do século, os periódicos lançados vão se tornando mais especializados, mas também com mais chances de circularem pelo país e fora. Os Estados Unidos, saídos da Guerra Civil, não só tenderam à unificação com a hegemonia do Norte, mais exatamente do Nordeste, sobre o Sul, como se industrializaram, se urbanizaram e se profissionalizaram a passos largos. A especialização dos profissionais e dos campos de conhecimento estiveram no coração desses processos.

Da segunda metade do século 19, destacam-se alguns periódicos que Davis (1919) considera mais adequado classificá-los como educational periodicals do que school journals, uma vez que pendem em escopo e temática aos saberes superiores especializados, começando da formação secundária preparatória para o college e a universidade. Dentre eles, Education (Boston, MA, 1880-1916), The Academy (Syracuse, NY, 1886-1892), Educational Review (Nova York, NY, 1891-1928) e School Review (Ithaca, NY, 1893-1979). 
Tabela 1 -

Periódicos educacionais especializados de final do século 19.

\begin{tabular}{c|c|c|c|c|c}
\hline $\begin{array}{l}\text { Nome do } \\
\text { periódico }\end{array}$ & $\begin{array}{c}\text { Educ. } \\
\text { secundária }\end{array}$ & $\begin{array}{c}\text { Educ. } \\
\text { estrangeira }\end{array}$ & $\begin{array}{c}\text { História da } \\
\text { educação }\end{array}$ & $\begin{array}{c}\text { Várias fases da } \\
\text { educação }^{17}\end{array}$ & $\begin{array}{c}\text { Atualidades e } \\
\text { variedades }\end{array}$ \\
\hline AJE (Barnard) & 2 & 27 & 32 & 36 & 3 \\
\hline Education & 11 & 8 & 10 & 51 & 20 \\
\hline Academy & 69 & 10 & 0 & 17 & 4 \\
\hline $\begin{array}{c}\text { Educational } \\
\text { review }\end{array}$ & 12 & 7 & 13 & 64 & 3 \\
\hline School review $^{18}$ & 53 & 6 & 10 & 28 & 3 \\
\hline
\end{tabular}

Fonte: Davis, 1919, p. 56. A tabela foi modificada por Mirian J. Warde.

Na tabela 1 há uma importante diferenciação entre o AJE de Barnard e os quatro periódicos que o sucedem, especialmente quanto aos espaços por ele reservados à educação estrangeira e à história da educação, por um lado, e a atenção conferida pelos demais à educação secundária.

Frutos do pós-guerra civil os quatro periódicos reafirmaram a vocação de Massachusetts e Nova York pelos impressos de elevado nível e alcance nacional, sendo que os editados e produzidos em Nova York foram considerados três dos mais importantes periódicos educacionais lançados Estados Unidos (Bardeen, 1893; Davis, 1919; Ryan, 1923). Além desse perfil, o Educational Review e o School Review trazem em comum uma característica dos novos tempos nos Estados Unidos de elevação dos estudos educacionais para o ensino superior: ambos estiveram sob a responsabilidade editorial de acadêmicos; o primeiro foi editado por Nicholas Murrary Butler ${ }^{19}$ do Columbia College e o segundo, por J. G. Schurman, presidente da Cornell University, e C. H. Thrurber, diretor da Colgate Academy.

Butler fundou e editou o Educational Review em um período crítico da reforma escolar norte-americana na qual ocorriam transformações e embates dramáticos. Para Mclnerny (1989), o ER emergiu como um periódico acadêmico e se tornou prontamente um dos mais importantes veículos de comunicação das reformas, e dos debates a seu favor e contra. A ER teria se tornado "uma revista líder ao oferecer um fórum para a discussão de filosofias da educação e ao representar a educação superior nos esforços de reforma" (Mclnerny, $1989 \mathrm{~s} / \mathrm{p}$ ), ao se centrar no avanço dos estudos científicos sobre a Educação e por ter se empenhado na profissionalização do ensino. Nas páginas da $E R$ foram reunidos importantes nomes e tendências que se confrontaram durante aqueles anos de reforma do ensino, em seus diversos níveis; nelas, por exemplo, estão bem representados os reformismos de John Dewey e o de Edward L. Thorndike.

A School Review: a journal of secondary education (1893-1979), fundada por Jacob Gould Schurman, presidente da Cornell University, é um dos melhores exemplos das novas tendências periodísticas no campo educacional norte-americano de fins do século

\footnotetext{
${ }^{17}$ Não incluídas anteriormente

18 Subtítulo: A journal of secondary education.

19 Nicholas M. Butler contribuiu diretamente para a integração do Teachers College à Universidade de Columbia, da qual seria presidente, tendo, anteriormente, respondido pela direção daquele College. A sua Educational Review ganhou uma medalha de ouro na Exposição Internacional de Paris em 1900. 
19. Subsididada pela Sage School of Philosophy da Cornell, a $S R$ teria preenchido um lapso deixado pelo fechamento de duas importantes revistas dedicadas ao ensino secundário, a Academy e a School and College, assunto de grande interesse não só para os envolvidos naquele grau de ensino como também aos responsáveis pelo ensino superior.

Não casualmente, a $S R$ foi lançada no mesmo ano em que dois comitês da National Education Association - NEA - divulgam seus relatórios a respeito da organização da escolar elementar e do currículo da escolar secundária que ressoaram polarizações de alcance estrutural $^{20}$.

O crescente interesse pela temática do ensino secundário manifesto pelo educational journalism estava estreitamente relacionado à sua grande expansão. $O$ número de escolas públicas do ensino médio - high schools - teria passado de $40 \mathrm{em}$ 1860 a 6.005 em 1900 mantendo a curva ascendente no século seguinte (Dunkel, 1975). Essa expansão teria abalado o equilíbrio que era mantido na sua relação bifronte com o ensino elementar e o ensino superior: continuidade do elementar ou preparatório para o superior? O crescimento vertiginoso das matrículas trouxe à baila fortes tensões entre os defensores dos antigos padrões de excelência e os defensores de reformas que, também se opunham entre si.

A $S R$ preencheu suas páginas com matérias sobre planos de estudo e o ensino de uma grande variedade de matérias, prescrições de como lidar com situações de ensino foram a tônica dos primeiros números, às quais se acrescentaram requisitos para o ingresso nas faculdades, o papel dos clássicos, o lugar do ensino da ciência, do Latim e da História, ou seja, candentes temas de um momento de incerteza sobre o que fazer com o secundário.

Em 1895, Charles Herbert Thurber havia se tornado o único editor da revista. No ano seguinte, transferindo-se para a University of Chicago, Thurber levou consigo a $S R$ a partir de então produzida pela editora da universidade ${ }^{21}$. Com a nova editoria, a revista ganhou em circulação, mas não perdeu a linha adotada anteriormente: independência das pessoas e dos departamentos onde fosse produzida e foco na temática da educação secundária. Assim se manteve, apesar das pressões que teriam sido feitas de dentro do Departamento de Filosofia, e depois de Educação, especialmente por John Dewey e George Locke, substituto de Thurber, para que a $S R$ ecoasse mais e melhor a produção intelectual dos membros do departamento (Dunkel, 1975; Wechsler, 1979, 1980).

Com a chegada de Charles Hubbard Judd à Universidade de Chicago, em 1909, a $S R$ entrou em um novo ciclo no qual se afirmou como um dos melhores periódicos norteamericanos seja pela densidade e originalidade dos artigos, seja pela notoriedade dos autores atraídos pelo editor. Dentro da Universidade de Chicago, Judd respondia aos planos originais de William R. Harper, presidente da universidade, de estabelecer os seus periódicos como o principal meio de divulgação dos novos conhecimentos produzidos na instituição e de exercício de influência em todo o país. Fora, Judd atraía contribuições

${ }^{20}$ Lembrar aqui o Report of the Committee of Ten e o Report on the Correlation of Studies in Elementary Education do chamado Committee of Fifteen, ambos datados de 1893. A respeito do segundo, ver neste dossiê o artigo de Rosa Fátima de Souza; sobre os dois relatórios, ver Kliebard, 1995.

21 Em 1893, Thurber assumiu a direção da Colgate Academy e a docência em Educação na Colgate University. 
importantes de proeminentes professores externos. Um exemplo relevante se pode extrair dos artigos de George Counts publicados na SR: na Universidade de Columbia, Counts era um dos importantes nomes nas fileiras do educational progressivism ao lado de John Dewey que se opunha ao reformismo de Edward Thornidke. Atraindo-o para a sua revista, Judd engrossava as fileiras de uma guerra que ele pessoalmente comandava contra o conexionismo ${ }^{22}$ e suas implicações no campo curricular (Jonçich, 1968).

Mudadas as circunstâncias, refluídos os tempos reformistas, estreitadas as especializações, novas tendências emergiram nos Estados Unidos modificando o periodismo educacional e a $S R$ em particular. A revista passou a contar cada vez menos com professores do ensino médio como autores e signatários, uma vez que se tornaram crescentemente cativos das revistas de temática ampla das suas associações e dependentes dos periódicos de seus grupos de especialização. Assim, como diz Dunkel (1975), a $S R$ se descobriu a terceira revista a competir pelo dinheiro e tempo do professor, com menos professores interessados em um segundo periódico de perfil geral em acréscimo àqueles das suas associações estaduais e de seus grupos de referência.

Concomitantemente, outra tendência pressionou os periódicos educacionais para mudança do seu perfil: a ênfase sobre pesquisa e a crescente sofisticação nas técnicas de pesquisa. Para os professores do ensino médio essa era uma demanda de difícil atendimento, consideradas suas condições de trabalho e formação.

Esses e outros fatores acabaram levando a $S R$, em 1957, a cancelar seu subtitulo a journal of secondary education - e a se tornar uma revista geral de educação, embora procurando evitar sobreposição com o Elementary School Journal, ao mesmo tempo suportando a concorrência de revistas acadêmicas com elevado nível técnico, como o Teachers College Record e muitos outros periódicos lançados ao longo do século 20, frutos da elevação dos níveis de formação e pesquisa no campo da Educação ${ }^{23}$.

\section{Considerações finais}

Muitas outras características do educational journalism do período abarcado por esta pesquisa deverão ser ainda examinados em futuros artigos. $O$ espaço aqui disponível permitiu uma caracterização geral dos estudos a respeito do tema e algum detalhamento a respeito das modalidades de periódicos lançados entre o século 19 e primeiras décadas do século 20 , bem como seus editores, seus locais de produção e seus destinatários potenciais.

Em estudos futuros devem ser objetos de atenção aspectos tais como: o reduzido número de editoras mulheres quando a presença feminina no magistério e até mesmo na autoria já era significativa desde meados do século $19^{24}$. Segundo Davis (1919), as primeiras importantes contribuições femininas aparecem no American Annals of Education, em 1834. As mulheres, diz ele, eram frequentemente eleitas pelas associações para os conselhos editoriais. Duas foram eleitas editoras do Michigan Journal of Education (1854), no entanto, pediram para seus nomes não aparecerem, apesar de

\footnotetext{
${ }^{22} \mathrm{O}$ conexionismo é uma psicologia elaborada originalmente por Edward L. Thorndike que explica a aprendizagem como sendo, fundamentalmente, um processo de formação de conexão ou vínculo entre uma situação e uma resposta e que a satisfação seria a principal força para formar uma conexão.

${ }^{23}$ Ver, neste dossiê, o artigo de Vera Valdemarin acerca do Teachers College Record.

${ }^{24} \mathrm{Ver}$, neste dossiê, o artigo de Wayne Urban relacionado com as mulheres na NEA. 
terem trabalhado muito. Para Davis (1919, p. 51), "essa modéstia", ocasionalmente manifesta, explica a prática generalizada de publicação de artigos não assinados e o fato de os artigos sobre método e aparatos serem os mais frequentemente citados sem crédito do autor, tornando difícil a identificação das mulheres na produção de material profissional, uma vez que elas eram as mais ativas nessa modalidade de trabalho.

Merecem atenção, também, os periódicos mantidos por diferentes igrejas ou denominações religiosas. Além de serem numericamente significativas ao longo do período examinado, revelam ciclos de vida relativamente mais longos do que os demais impressos seriais, especialmente aqueles direta ou indiretamente ligados às escolas públicas, o que sugere bases administrativas mais estáveis e fontes de financiamento mais sólidas.

Por fim, destaque-se o número significativo de periódicos em cujos títulos há referências à família e ao lar. Foram anotados 12 periódicos com referência à família publicados entre 1832 e 1859. Com referência ao lar foram identificadas 30 revistas publicadas entre 1856 e 1908. Na quase totalidade os títulos mencionam a escola e o lar ou a escola e a educação/instrução no lar. A relevância desses impressos lançados ao longo do processo de afirmação da escola pública norte-americana é indiscutível, uma vez que permitem um acompanhamento mais minucioso do peculiar envolvimento das famílias norte-americanas na construção dos sistemas públicos de ensino.

\section{Referências}

ACKERMAN, Mary M. Henry Barnard and universal public education as the responsibility of a democratic society. New Haven, CT. 1968. 49f. Thesis (master of Science). Southern Connecticut State College.

ALEXANDER, Carter. Some present aspects of the work of Teachers' Voluntary Associations in the United States. New York: Teachers College, Columbia University, 1910.

American Journal of Education (The). v. I, 1856.

American Journal of Education (The). v. XII, 1862.

American Journal of Education (The). v. XIV, 1864.

American Journal of Education (The). v. 19, 1869.

American Journal of Education (The). v. 20IV, 1873.

American Journal of Education (The). v. 20V, 1876.

American Journal of Education (The). v. 20VII, 1877.

American Journal of Education (The). v. 20VIII, 1878.

BARDEEN, Charles W. Educational journalism. An address before the New York State Teachers' Association at its thirty-sixth annual meeting, Saratoga Springs, August 7, 1881. The School Bulletin Publications. Syracuse, NY: C. W. Bardeen, Publ., 1881.

BARDEEN, Charles W. The history of educational journalism in the State of New York: a paper read July 28m 1893, before the Department of Educational Publications of the International Congressed of Education of the World's Colombian Exposition. Syracuse, NY: C. W. Bardeen, Publ., 1891. 
BARNARD, Henry. Normal schools and others institutions, agencies, and means designed for the professional education of teachers. Part I. United States and British Provinces. Hartford: Case, Tiffany and Company, 1851a.

BARNARD, Henry. Normal schools and others institutions, agencies, and means designed for the professional education of teachers. Part II. Europe. Hartford: Case, Tiffany and Company, 1851b.

BARNARD, Henry. Educational periodics in the United States. American Journal of Education (The). v. XV, 1865, p. 383-384.

BASTOS, Maria Helena C. O novo e o nacional em revista: a Revista do Ensino do Rio Grande do Sul (1939-1942). São Paulo: USP, 1994. 350f. Tese (doutorado em Educação). Programa de Pós-Graduação em Educação, Universidade de São Paulo.

BICCAS, Maurilane S. O impresso como estratégia de formação: Revista do Ensino de Minas Gerais (1925-1940). Belo Horizonte: Argumentum, 2008.

BOURDIEU, Pierre. Algumas propriedades dos campos. In: BOURDIEU, Pierre. Questões de sociologia. Rio de Janeiro: Marco Zero, 1993, p. 122-155.

CATANI, Denice B. Educadores à meia-luz: um estudo sobre a Revista de Ensino da Associação Beneficente do Professorado Público de São Paulo (1902-1918). Bragança Paulista: USF, 2003.

CARVALHO, Marta M.C. Pedagogia da escola nova e usos do impresso: itinerário de uma investigação. Revista do Centro de Educação, Santa Maria: UFSM, 2005, p. 87-104.

CARVALHO, Marta M. C. de. Modernidade pedagógica e modelos de formação docente. São Paulo em perspectiva, v. 14, n. 1, 2000, p. 111-120.

CASPARD, Pierre (dir.). La presse d'éducation et d'enseignement, XVIIle siècle - 1940: répertoire analytique. Paris: INRP/CNRS, 1981-1991.

CASPARD-KARYDIS, Pénélope (dir.). La presse d'éducation et d'enseignement, 19411990: répertoire analytique. Paris/Lyon: INRP, 2000-2005.

CATANI, Denice B.; BASTOS, Maria Helena C (orgs.). A imprensa periódica e a história da educação. São Paulo: Escrituras, 1997.

COLLINS, E. A. Contributions to educational periodicals. Peabody Journal of Education, v. 6, n. 5, 1929, p. 278-281.

Common School Journal, v. I, 1838.

DAVIS, Sheldon E. Educational periodicals during the nineteenth century. Washington: Govr. Print Off, 1919.

District School Journal for the State of New York, v. I, 1840.

DUNKEL, Harold B. Guest-editorial: re-viewing school review. The School Review, v. 83, n. 3, 1975, p. 391-396.

Educational Writings. The Elementary School Journal, v. 15, n. 2, p. 68-81, 1914.

Educational Writings. The Elementary School Journal, v. 15, n. 7, p. 344-354, 1915.

FOOS, Charles S. State Educational associations. Annual Report of U.S. Commissioner of Education. v. II. Washington D. C.: U.S. Government Printing Office, 1909, p. 251-274.

GOOD, Harry G.; TELLER, James D. A history of western education. New York: The MacMillan Co., 1969. 
HANZLIK, Christie C. Education beyond borders: exchanging Ideas through World's Fairs, Congress, and Academic Journals, 1851 to 1904. Madison, WI: UW, 2010. $267 f$. Dissertion (doctor of Philosophy). University of Wisconsin.

HART, Albert B. The teacher as a professional expert. The School Review, v. 1, n. 1, p. 414, 1893.

HUDSON, Frederic. Journalism in the United States from 169070 1872. New York: Harper \& Brothers, 1873.

JONÇICH, Geraldine. The sane positivist: a biography of Edward L. Thorndike. Middletown, CT: Wesleyan University Press, 1968.

KELLY, E. Lowell; WHITNEY, Frederick L. Educational magazines read by five hundred elementary-schools principals and classroom teachers. The Elementary School Journal, v. 29, n. 3, p. 176-180.

KIRK, Hyland C. A history of the New York State Teachers' Association. New York: E. L. Kellogg \& Co, 1883.

KLIEBARD, Herbert M. The struggle for the american curriculum (1893-1958). New York: Routledge, 1995.

McINERNY, Paul M. A historical study in educational journalism: the educational review, 1891-1919. Milwaukee, WI, 1989.

MONROE, Paul (ed.). A cyclopedia of education, v. II. New York: The MacMillan Co., 1919 MONROE, Paul (ed.). A cyclopedia of education, v. III. New York: The MacMillan Co., 1918.

MONROE, Paul (ed.). A cyclopedia of education, v. IV. New York: The MacMillan Co., 1918.

MONROE, Will S. History of the pestalozzian movement in the United States. Syracuse, NY: C. W. Bardeen, 1907.

MONROE, Will S. The educational labors of Henry Barnard: a study in the history of american pedagogy. Syracuse, NY: C. W. Bardeen, 1893.

MOTT, Frank L. A History of American Magazines, 5 v. Cambridge, MA: Harvard University Press, c1958-1968.

NATIONAL EDUCATION ASSOCIATION OF THE UNITED STATES. Classified list of educational periodicals. Washington, DC: NEA, 1930.

NÓVOA, António. Histoire \& comparaison: essais sur l'éducation. Lisbonne: Educa, 1998.

RYAN Jr., W. Carson. Recent developments in educational journalism. Department of the Interior. Bureau of Education. Washington, D.C.: Govr. Printing Off, 1923.

SHANNON, J. R. Contributors to educational periodicals. The Elementary School Journal, v. 32, n. 3, 1931, p. 177-182.

TEBBEL, John W. A history of book publishing in the United States. Volume II: The expansion of an industry, 1865-1919. New York: R. R. Bowker Co., 1975.

THARP, Louise H. Until victory: Horace Mann and Mary Peabody. Boston: Little, Brown and CO, 1953.

THURSFIELD, Richard E. Henry Barnard's american journal of education. Baltimore: The John Hopkins Press, 1945. 
TOWNE, Geroge L. The educational journal. The Journal of Education, v. 69, n. 8, 1909, p. 204-206.

WARDE, Mirian J. A industrialização das editoras e dos livros didáticos nos Estados Unidos (do século 19 ao começo do século 20). Educação e Sociedade, v. 32, n. 114, 2011, p. 121-135.

WECHSLER, Harold S. The Primary Journal for Secondary Education, 1893-1938: Part I of a History of School Review. American Journal of Education, v. 88, n. 1, 1979, p. 83-106.

WECHSLER, Harold S. From practice to theory: a history of school review, Part II. American Journal of Education, v. 88, n. 2, 1980, p. 216-244.

MIRIAN JORGE WARDE é professora visitante no Programa de Pós-Graduação em Educação da Universidade Federal de São Paulo - campus de Guarulhos. Pesquisador sênior do CNPq.

Endereço: Av. Monteiro Lobato, 679 - 07112-000 - Guarulhos - SP - Brasil.

E-mail: miwarde@uol.com.br.

Recebido em 20 de junho de 2015.

Aceito em 4 de setembro de 2015. 